\title{
EL ORIGEN DE LA CATEDRAL: ESTÉTICA ESCOLÁSTICA E IDEOLOGÍA ECLESIÁSTICA
}

\author{
José Enrique Ruiz Doménec
}

No pensamos aún el tema de la catedral en forma suficientemente decidida. Se conoce la catedral gótica como un estilo artístico, como una obra de arte, como una categoría estética, pero la catedral en sí misma permanece al margen de la historia social. Permanece al margen y, además, conscientemente margirada. Ninguno de los elementos problemáticos que la catedral sugiere, ha impulsado al historiador a un intento explicativo. La elípsis es la única reacción que parece advertirse en la actualidad sobre este problema. El pensamiento histórico, casi en su totalidad, aduce que la catedral es un tema que no le compete; que sólo es reducible a su campo de significaciones, y que, aún en ese campo, el historiador debe permanecer cautamente silencioso. Lo que en este proceso de pensamiento se oculta, apenas hoy somos capaces de sospecharlo. La liberación del tema de la catedral del prudente silencio al que la historia la ha sometido es la exigencia más inmediata. El pensar teórico que la historia social desarrolla hoy día, no es sólo una correcta sistematización de los problemas materiales y sociales; es también una real solución para los problemas 
estrictamente imaginarios que emergen en un momento determinado. La historia social quiere, y se exige de sí misma, comprender la condición y la situación de los hombres y de la cultura. De ahí que debemos consumar el campo propio de su exigencia teórica al desarrollar el tema de la catedral; de este modo podremos aprender a descubrir la clave de los problemas que tienen encapsulada la catedral. Esto quiere decir, que debemos liberar los temas que permanecen en silencio de su razón-de-estancia-abr.

Esta es la misión que me he impuesto desarrollar esta mañana ante Vds, en este "Auditorium Valls y Taberner del Achivo de la Corona de Aragón de Barcelona». Y lo tendré que hacer, aunque sea pausadamente. No me importa desplegar el tema en su complejidad, aunque sé que estoy acosado por el límite del tiempo y no es cuestión de perder aquí el prestigio y el valor por ampliar excesivamente el campo de interrogaciones. Lo cual no quiere decir que pretenda resolver los problemas que la historia social ha heredado sobre el tema de la catedral gótica según criterios de clasificación estructuralmente cómodos. Juzgaré necesario meditar con detención sobre algunos de los puntos que han sido presentados inadecuadamente por la bibliografía al uso. Este juicio que desarrollo anticipadamente, sólo pretende llamar la atención y valorar en su conjunto el nivel y el grado con el que se ha expuesto el tema de la catedral gótica. Hace tiempo, hace demasiado tiempo, que la catedral está situada en el silencio. ¿Puede llamarse "pretensioso" el esfuerzo de llevar a cabo un intento interpretativo según los modelos teóricos que la historia social exige?

La serie de problemas que el tema de la catedral gótica sugiere exigen una respuesta inmediata. Ante todo, porque la catedral es el nombre de aquella institución que ha preocupado desde siempre al medievalista. El rigor de cualquier intento de síntesis sobre esa Edad Media que tanto nos exige y de la que tan poco sabemos en realidad, no consiste tan sólo en seguir la huella, con una exactitud técnico-teórica, de los 
conceptos, de los grupos sociales o de los niveles de la productividad. El rigor consiste también en que sepamos contestar a las preguntas que la misma sociedad medieval nos legó con la sencillez de una obra artística en sus diversas dimensiones. Una obra de arte, y la catedral gótica lo es, ofrece una lectura de inquietud que sólo la cuidadosa interpretación de la historia social puede discernir. Por eso, hoy he querido elegir de forma consciente una de las preguntas básicas que la sociedad de la segunda mitad del siglo XII y del XIII nos planteó cuando comenzó a construir catedrales en el suelo europeo. La primera tarea es la réspuesta a ser interrogante, que puede ser implícito pero que, surgiendo de la experiencia de otros campos epistemológicos (la filosofía, el análisis hermenéutico de la literatura, etc.,), emerge explícitamente. He ahí la razón por lo que la elucidación del tema de la catedral, respuesta al interrogante de la catedral en sí, arroja luz sobre el conjunto de la sociedad.

La pregunta es ésta: ¿La catedral gótica tiene algún significado social? Desde el fondo mismo del interrogante surgen las razones por las que la sociedad en torno al afno 1140 empezó a construir catedrales. La pregunta nace del propósito mismo de mantener la razón exacta de lo que se ha denominado gótico. Y ello es necesario. La catedral impone su presencia de forma absoluta, suficientemente probada por la solvencia de sus muros, por la energía de su espíritu creativo, por la altivez de sus encuadres programáticos. Silenciar la catedral y la pregunta que la presenta en historia, es desconfiar de la realidad de aquella época y seguir abriendo el campo mismo a la serie de supuestos eidéticos que han construido una visión del mundo medieval tan compacta como falsa. No es que se vaya a resolver aquí el goticismo, en el sentido que quiso Whilhelm Worringer ${ }^{1}$. Quizás tan sólo, porque hace tiempo que se desconfía de los "ismos» en el mundo contemporáneo, y la historia social ha advertido lo ilegítimo de la demanda que ellos programaban. No es goticismo lo que se busca, sino la lógica de una construcción arquitectónica que fue más allá de sí misma para abarcar el universo creativo de la sociedad durante más de un siglo.

1 WILHelm WorRINGer, Formprobleme der Gotik. München, 1911. 
Este es el tema central donde el pensar puede perderse con facilidad en el poetizar ${ }^{2}$. La catedral toca-de-cerca los problemas de una poetización general del universo: sus muros exigen la conversión de unas imágenes, inicialmente sonoras, en conmociones de color, en sentimientos que suenan aún entre las llanuras, $y$, fundamentalmente, en la apertura de un espacio que expresa con densidad la existencia de los hombres entre 1140 y 1270 . El elemento que encierra todo este conjunto es la catedral misma, donde tienen lugar los supuestos más decisivos de esta sociedad sobre sí y sobre su propio mundo. Expresar las ansias es aspirar a conseguir su dominio omniinclusivo, mediante la disolución del anterior y la concentración de su presencia intelectual sobre la esencia de las palabras y las cosas. La catedral es, dicho llanamente, la ideología que conformó aquel mundo.

Cuando he hablado de la silenciosa fuerza que ha mantenido a la catedral al margen de la teoría de la historia social, no sólo he querido sostener la dimensión de una actitud ante un tema imposible, sino lo candente de esta actitud: la preocupación y la duda que ha embargado al medievalismo desde que topó con la catedral como exigencia humana y social. Tener capacidad de resolver el problema quiere decir aquí: forjar la tesis, suprimiendo las contradicciones que la historiografía clásica había advertido sobre el tema de la catedral. Sugerir la razón última de esa preocupación existencial y social, y sustituir su mirada opaca por una que penetre dentro de las exigencias culturales del mundo actual.

El dominio de tales actitudes sobre la catedral no es casual ni aleatorio. Se enmarca dentro de la exigencia que tienen de explicar lo significante de la catedral: ese mundo de representación de objetos que parece tener en su seno. Por eso mísmo, cuando el objeto de preocupación último, religioso, político, social o simplemente arquitectónico, está más cerca de la catedral, más problemática y angustiosa aparece la respuesta al tema mismo. La existencia de la catedral resulta incuestionable, pero no su significación. Ésta sigue siendo el

2 Si me pierdo en ocasiones es simplemente por la fidelidad al magisterio que impone MARTIN Heidegger, en su Nietzscbe Verlag Gunther Neske, Pfullingen, 1961, pp. 11 ss. "der Wille zur Macht als Kunst». 
punto de contacto explicativo de una ideología y su público, y se alimenta de las diversas oscilaciones ideológicas que el europeo ha tenido sobre sí mismo y sobre su pasado desde hace más de cien años. Así, la catedral es testimonio de una forma de acceso al pasado y a su interpretación, y, más específicamente, de la esclavización de muchos individuos a los sistemas de valores de su momento. Pero esto mismo nos ayuda a comprender por negación los condicionamientos internamente existenciales y objetivamente sociales que han logrado dominar el criterio intelectual-teórico del saber histórico. Por eso en el lenguaje corriente, el cotidiano que utilizamos normalmente, y con el que incluso los eruditos se acercan a la mass media, se desarrolla un tipo de planteamiento de la catedral groseramente uniforme, simplificado en sus contornos, y escolar en su nivel. No es el límite que separa la alta cultura con la cultura de masas, es simplemente la desantención que se tiene acerca del rigor histórico de un problema. Puesto que catedrales góticas parecen emerger en diversos lugares y en diversas épocas, resulta inevitable hablar ligeramente de ellas. Así cae el tema de la catedral gótica - y así ha caído desde hace más de un siglo- bajo la dictadura de los publicitarios de mal gusto, de los ensayistas miopes y de todo tipo de acceso rigurosamente impresentable tanto por su valor como por su gusto. Esta frívola actitud ante la catedral gótica, que arraiga en la crisis de la alta cultura y en la desasosegada pasión por el conocimiento tipoReader-Digest, decide de antemano, y en expresión periodísti$\mathrm{ca}$, lo que debe ser rechazado. Lo curioso del caso es que ante esta actitud, ligeramente paternalista, se afianzan las observaciones más reaccionarias y las tesis más inmovilistas sobre la cultura medieval y sobre el conjunto teórico-operativo del gótico. La pregunta, que he sugerido al principio de mi lección, zozobra ante este estado semisalvaje de la cultura en el día de hoy. Es la contribución última que la llamada sociología del arte ha tenido sobre estos temas.

Lo dicho hasta ahpra contiene una referencia de orden negativo. Parece como si tratase de eludir la cuestión planteada, y presentase ante $V$ ds. sólo una serie de alegatos éticos-existenciales del actual historiador social sobre lo que no debe hacerse. Pero es que, en ocasiones, se ha hablado de la catedral gótica sin rigor, tratando sus esencias, sus viven- 
cias, sus vinculaciones con el neoplatonismo, el pitagorismo, la mística poética alemana, etc., sin determinar el campo de la investigación: ese espacio concreto, ese tiempo determinado, esa razón precisa. Dónde, cuándo, por qué, cómo, son los interrogantes que dilucidan severamente la cuestión fundamental del significado estricto de la catedral gótica.

Esta dimensión histórica, única realización posible de un programa que quiera determinar con exactitud un tema imaginario de la sociedad, queda oculta bajo el dominio de la subjetividad que se presenta con evidente sentido publicitario. El tema de la catedral trasciende por sí mismo la simple curiosidad erudita, instalándose como una preocupación última, ya lo he dicho, psicológicamente emanada de la ideología que impere: he aquí la dimensión publicitaria de la catedral $^{3}$. Se concreta este tipo de preocupación en un acercamiento estilístico, eidético o sociológico, convirtiéndose, entonces, en una reflexión abstracta que logra abarcar y explicar el mundo del presente sobre el de su pasado. Es como si la obertura del Parsifal de Richard Wagner alcanzara el rango de lenguaje cósmico y permitiese intuitivamente un acceso a la dimensión espacial que en aquel tiempo tuvieron los hombres que construyeron catedrales. La rápida, la creciente, la general reacción que el tema de la catedral ha provocado, impulsa el sentido de esa responsabilidad estética, moral o social. Y este conflicto, estrictamente existencial, emerge con nitidez allí donde existe una ansiedad gótica, abierta o enmascaradamente. De igual forma, se manifiesta en los trabajos que tratan de plantear la dimensión de esa catedral, ya sea cuando se describe por el estilismo, cuando se contempla por las «ideas» que se observan a su trasluz, o se comprende supuestamente al explicar su dimensión social. Este uso extremadamente negativo que se ha llevado a cabo sobre el tema de la catedral, ha alcanzado un nivel conflictivo que se atestigua en el peligro que se tiene hoy día de olvidar o silenciar el tema y dejarlo dominado por su reducción clásica. En cualquier caso, es precisamente nuestra situación ante el espectro de esa serie de interpretaciones y su

${ }^{3}$ MarCel. Brion, La Religion des français. Paris, 1972. Cf. apéndice sobre el mito de la catedral. Sobre el carácter de la propaganda nacionalista y el arte gótico, véase Pifrre Francastel, Frontières du gotbique. Paris, Mouton \& Co. 1970 (la primera edición es de 1945), capítulo primero, pp. 13 ss. 
conflictividad quien legitimiza la exigencia de recurrir al método de la historia de las sociedades medievales como el único medio para dominarlo.

La catedral es la única prueba existente para llevar a cabo este fin. Es la prueba irresistible. Es ella misma quien constantemente nos impide reducir su campo de experiencia y su significación a las interpretaciones existentes. La catedral se encomienda por sí sola a querer representar su universo de otra manera, alcanzar su sentido hermenéutico según criterios que le sean propios. La catedral en una palabra exige un tratamiento por alteridad. Esto mismo aparece en la textura de las obras literarias que surgieron paralelamente ( $y$ es muy posible que en sentido conjuntivo) a la catedral gótica ${ }^{5}$. Con ambos aspectos se puede construir una dimensión más coherente de ese universo gótico, solemnemente supuesto por la teoría clásica, pero nunca analizado con la severidad necesaria. Tan sólo por su presencia, la catedral es destrucción y exterminio de una visión del mundo medieval aproximativa e incierta. Su realidad exige una mayor profundidad en las interpretaciones para que, calculando y obrando sobre sus elementos, se logre abrir una dimensión en su grado de significación.

A esta actitud se acercó ya la primitiva erudición que trató sobre la catedral: la que surge en el mundo romántico y culmina en la obra de Wilhelm Worringer y el expresionismo. Con sus suposiciones arquitectónico-normativas, los expresionistas, a principios del siglo $\mathrm{xX}$, llevaron a cabo su sueño de utopía arquitectónica sobre una recuperación supuesta e ideal de la construcción gótica y, en especial, de la catedral. A esta línea pertenece la aseveración de que la catedral es un misterio de organización del universo. El propio Worringer hablaba de un "gótico secreto" que creía

${ }^{4}$ La idea de alteridad la analiza HANS-ROBERT JAUSS, Alterität und Modernität der mittelalterlicben Literatur. Wilhelm Fink Verlag, München, 1977. La idea de orden fenomenológico aparece en H-G. GADAMER, Wahrbeit und Metbode. Tübingen, 1960.

'Relación estrecha que establece entre otros G. WEISE, Italien und diegeisge Welt der Gotik. Halle a. Salle, 1939, pp. 61 ss. Y Hans SEDLMAYr, Die Entstebung der Katbedrale. Zurich Atlantic Verlag, 1950. Reedición, Akademische Druck-v. Verlagsanstalt Graz. 1976. Cito por la presente edición, pp. 334 ss. 
ver en acción antes y después del periodo gótico propiamente dicho. Karl Scheffler iba incluso más allá: clasificaba sumariamente el arte prehistórico, egipcio, indio, chino y barroco como estilos "góticos". Era la gran convulsión wagneriana del mito místico ante el misterio de las ojivas que se elevaban como imposibles hacia lo-nunca. No hay nada de extraño en ello. Es el descendimiento simple por la piedra hacia la búsqueda de la blancura de los árboles de la vida, como si fuesen nubes plateadas, espacios enajenados o ideas como luces. Desde Gaudí hasta Wilhelm Worringer, Karl Scheffler, Wilhelm Kris, Hans Poelzig, e incluso Frank Lloyd Wright, todos intentaron re-pensar de nuevo aquel instante de verdad (el espíritu gótico), lamentándose de no encontrar ni siquiera en la tradición hermética la clave de la claridad.

A pesar de todo, había en ellos un resto de verdad. Porque cercanos a la dimensión exacta de la conciencia de la catedral gótica, el expresionismo, antes de perderse por los pasillos azulados, aprendió a permanecer cerca de los problemas en su sentido puro. De igual modo, él nos enseñó a reconocer la impotencia que nos embarga ante un tema de la envergadura de la catedral gótica. Y tanto Worringer, como Scheffler y otros muchos nos previnieron contra la publicidad negativa y de cartón-piedra que terminaría organizando la pesadilla de las nuevas Metrópolis.

Pero con esta tesis no se encontró nada más que el límite con la realidad. El expresionismo nos puso ante la idea misma de que la catedral era, utilizando el concepto como hizo Hegel, un problema. Sólo así se podría entender una cuestión que sobrepasaba, y con mucho, las dimensiones teóricas y técnicas de aquellos intelectuales. Era la vivencia radical de que algo existía en la sociedad europea cuya reducción a lo mistificante era la exigencia de su intrínseca dificultad. Hegel incluso halló para la fenomenología del espíritu un principio absoluto que supuestamente también lograse abrir el campo a los problemas insolubles. No pensaba el sabio alemán en la catedral gótica, pero bien pudiera haberlo hecho porque a partir de él, y de su influencia implícita, la catedral se convirtió en una idea donde moraba la verdad de una época y de un mundo.

La verdad quizá no, la realización mundanal, posiblemente sí. Esta es, paradójicamente, la enseñanza que la dialéctica 
del espíritu de Hegel ha legado: desbrozar con legitimidad la pesadilla epistemológica heredada. Y mi tesis es que la pesadilla comenzó con la catedral. Es nuestro "cuidado" inicial, casi arcano, de la existencia. Nuestra tínica dimensión distante de lo-azul.

Pero ¿dónde y cómo se determina la naturaleza de este problema? Karl Marx exigiría un conocimiento absoluto del nivel de las fuerzas productivas y de las relaciones de producción, junto a un grado elevado de la determinación de los principios de legitimización de la sociedad de su época. A esta cuestión respondería por lo tanto que el problema de la catedral se resolvería si se ampliase el campo al problema del conjunto de la sociedad que la engloba, y del que la catedral sólo es una parte (no una superestructura como han dicho algunos de sus seguidores más miopes). La catedral sería para él un elemento más de lo social inmediato: el modo de producción. En la explicación de la naturaleza de la sociedad del siglo XII y del siglo XIII (entre 1140 y 1270), Marx vería (y digo vería porque Marx nunca estudió este problema) la explicación del tema de la catedral. Al igual que Hegel, ampliaría el campo a la totalidad extensiva social para demandarle una explicación sobre el tema de la catedral. Es el buen camino, aunque modernamente parece que ha encontrado algunas dificultades. Pero es el buen camino porque empieza detectando lo que inicialmente es la catedral: un problema. Y como todos los problemas, requiere un planteamiento previo que intente abordarlo. El marxiano (y quizás no el marxista) consistiría en demandar a la totalidad extensiva de lo social esa exigente acción. De todos modos, y en eso Marx tiene toda la razón, el acceso ha de ser teórico en la medida en que la catedral ha fustrado toda una serie de intentos interpretativos sobre la sociedad medieval. Su imposición es material; reside en su presencia físicamente incuestionable (aunque muchas catedrale terminasen en el siglo XIX y XX, como Barcelona, Mi. - o Colonia). La catedral explicaría, según Marx, las demanías naturales más inmediatas, las pulsiones objetivas, de las que hablaba Ernst Bloch. Ensayando este camino en su sentido preciso, como luego veremos, se ha obtenido una ampliación decisiva del campo teórico de lo imaginario de la sociedad medieval. Se ha abierto la experiencia a detectar en la formación y 
construcción de la catedral gótica no sólo la experiencia de una visión del mundo, sino las transformaciones profundas en el modo de producción señorial.

Hay otra forma de acceso, aceptando también que la catedral es un problema: la fenomenológica. Su apertura al mundo es crítica con respecto a la consideración anterior; postula que la clave de la explicación de la catedral está en los fenómenos que ella misma nos informa, Que tras el conjunto de representaciones se esconden unas imágenes del mundo y un sentido de la estética que abre el campo a una interpretación vigorosa. Incluso Eugen Fink ha llamado la atención sobre el sentido técnicamente correcto que tiene la ampliación del campo de la experiencia fenomenológica al tratamiento de problemas ontológicos concretos ${ }^{6}$. Y la catedral gótica, ya lo he señalado, es uno de ellos. En un momento determinado de la evolución de la sociedad medieval se encuentra el gótico. De ahí que éste sea un fenómeno específicamente medieval, surgido del encuentro de una situación particular de las exigencias culturales y de un cierto nivel técnico. El gótico es algo así como un conjunto de fenómenos que estructuralmente sobrepasan en intensidad y alcance las relaciones ordinarias y se inscriben como una estructura latente en el acervo cultural inmediato de los hombres medievales a partir de un momento determinado. La fenomenología termina, como se ve, con un lamento crítico. Porque ese significado de la catedral del que tanto se ha hablado, se ha inscrito como un modelo de comportamiento, como una necesidad óntica en el acervo cultural; aunque no se sabe muy bien las razones de ese arraigamiento. A lo sumo, y ampliando el campo, patéticamente, al nivel existencial, podría decirse que la catedral es guardián del arte gótico, como estaría inclinado a creer Martín Heidegger?

Toda interpretación fenomenológica arranca de un intento de descripción a partir de lo-que-no-es-la-catedral, observando con detalle aquellos aspectos particulares que nos

${ }^{6}$ EUgen Fink, Sein and Mensch. Wom Wesen der ontologiscben Erfabrung, Veriag Karl Alber, Freibur-München, 1977. Sobre el valor de la imagen y ia re-presentación, véase del mișmo Studien zur pbànomenologie. Martinus Nijhoff, La Haye, 1966.

Cf. Martin Heidegger, Holzwege, Vittorio Klostermann, Frankfurt, 1950. 
lleven a reafirmar lo que existe de abismal en la obra de arte gótica. Sin embargo, el análisis fenomenológico acentúa la oscuridad del tema al silenciar la razón de ser de todo el gótico, y, más aún, de la catedral. Esto se hace notorio en aquellos trabajos que tratan de superponer un acercamiento teóricamente intuitivo al tema de la catedral, junto con un análisis severo y exhaustivo de cada uno de los elementos plásticos que componen la obra de arte que indefectiblemente es la catedral gótica. En este sentido restrictivo, se entiende la catedral como una sustancia, en sentido real, activa y pasiva, que aparece y desaparece en el tiempo y en el espacio. La historicidad de los argumentos queda obstaculizada por la exigencia explicativa de que existen catedrales en el siglo XII en la Isla de Francia, o en el siglo XV en las fronteras de la cristiandad latina, como en Sevilla.

Idea, elemento extensivo y sustancia, son los tres caminos modernos de realización del tema de la catedral. El intelectualismo del pensamiento de Worringer y el expresionismo, el humanismo social de Marx y los marxianos, y el humanismo existencial de los fenomenólogos, en especial de Heidegger, conciben teóricamente el campo estético bajo un prisma doctrinal, cuya finalidad y fundamento coinciden en su nivel ontológico y discrepan en la naturaleza de la forma de acceso, es decir, del tema de su realización: de la catedral gótica. De esta manera, se han constituido, y se constituyen las dudas sobre este grave problema. Lo propio del historiador social ha sido olvidarlo o suponerlo, nunca buscar la razón estricta de su dificultad determinante. De ahí que si aún hoy nos acercamos a la razón de ser del problema, veremos que el tema de la catedral resulta aún imposible de solventar y que su imagen real e histórica queda perdida en la espiral de la oscuridad de un bosque sin sendas que no logra ser desbrozado por la lógica del saber histórico. Al contrario, la necesidad y el modo propio del tema olvida esta lógica o oscurece el tema hasta la simplificación eidética, estilística o sociológica.

La catedral representa, ciertamente, el nudo problemático de la realización de la sociedad medieval, y piensa sus ritmos internos según el modelo que ella impone. Pero no piensa la catedral como-lo-que-es. Nunca se ha preguntado por ella misma sino por su fenómenos estilísticos, ideales o 
sociales. De ahí que no debe resultarnos extraño que ni Wilhelm Worringer, ni Hans Sedlmayr, ni Otto von Simson ni Louis Grodecki - por no citar sino a los autores más relevantes de esta cuestión ${ }^{8}$ - hayan logrado salirse de la tesis que advierte la catedral como simple proyección. Pero esta postura no sólo ha con-formado, hasta ahora, toda interpretación sobre la catedral, sino que además denota la situación misma del tema. La idea de la proyección de sus elementos fenomenológicos constituye el único alcance posible en esta serie de estudios: sea la proyección del fenómeno del espíritu gótico como cree Worringer, sea la proyección del fenómeno de la idea eclesiástica como cree Sedlmayr, o sea simplemente la proyección del fenómeno del neoplatonismo y el pitagorismo como cree Simson. La catedral en estos excelentes trabajos espera hacerse caudal de inteligibilidad. Pero su espera es indefinida, y no logra realizarse en las páginas de estas densas monografías. Igualmente, todos ellos (e incluso sus imitadores menos notables) descienden a un abismo oscuro, para andar errantes por la incertidumbre, dentro de la cual aparecen las tesis más supuestamente sensatas sobre la catedral. Pero además, y antes que otra cosa, esta búsqueda se torna estéril, decidiendo de antemano lo que es la catedral, el análisis de ella no es sino una ampliación cognoscitiva de la idea ya concebida. Se podría afirmar que existe algo justo en la interpretación del gótico, pero debe quedar perfectamente claro que con este tipo de argumentaciones el tema de la catedral permanece oculto bajo el fantasma de la obra de arte. Se piensa en la decisión programática de este hecho, y se esconde para siempre la obra de arte, no en el arte, sino en la propia obra. Esta ontologización radical del problema repercute en todo intento de análisis de la estética del gótico y de la teoría social que la exige. Se piensa siempre que el principio operativo es un conjunto de variaciones técnicas o eidéticas y, sobre ellas, la catedral se advierte como un simple receptáculo. Esta suposición es el modo de presentar la catedral en el lenguaje habitual de los historiadores del arte y la cultura. Pero, por

- W. Worringer, Formprobleme der Gotik, 1911. H. Sedlamayr, Die Entstebung der Kathedrale, 1950. O. von Simson, The Catbedral. Origins of Gotbic Architecture and the Medieval Concept of Order. New York, 1956. L. GRODECK1, "L'Interpretation de l'art gothique», en Critique, 1952". 
ello, se atiende precariamente a lo esencial de la catedral, a su exigencia de ser un proceso histórico en un momento determinado. La catedral piensa la sociedad como un todo omniinclusivo, basándose en su propio saber, que se encierra en la certeza de sí misma. En estos trabajos, la catedral, podría decirse parafraseando a Martín Heidegger, ha oscila do en un análisis verde-vacilante.

La catedral se cierra al contenido fenomenológico de sus elementos, y sólo se deja entrever cuando se abandona esta actitud, para solicitar su campo de acción inmediato, con respecto al mundo que le rodea y a su universo imaginario. Sólo desde esta solicitud se puede captar la dimensión de receptividad que la catedral como objeto tiene para nosotros en el día de hoy. Captar, asimismo, su secuencia histórica determinada, su caudal de inteligibilidad, e incluso su sueño. Esta iluminación del tema de la catedral, que Heidegger denominaría $e c$-sistencia del ser al-estar-cercano-a-st, es propia de un objeto que tiene una densa particularidad de ser a la vez obra y arte. La catedral así entendida pertenece por alteridad al campo del análisis hermenéutico: ella es, rigurosamente hablando, una fuente histórica.

Ahora bien, al contemplar el tema de la catedral en esta dimensión, asaltan una serie de problemas que es necesario advertir. La cuestión gira en torno al grado de acceso dialéctico que se llega a admitir en el estudio de la catedral. El punto de partida más impresentable en la actualidad es el que conduce a la sociología del arte. Esta disciplina sólo se ha decidido por el principio motor de la dialéctica social, el que sostiene que la catedral es una proyección sobre algo que intenta a su vez comprender y conformar. Ese algo es obviamente la sociedad que la acoge, y sobre la que forma parte indesligable. Admitido esto, la sociología del arte simplifica los grados de presentación de la catedral en la sociedad europea entre 1140-1270 suponiendo principios categoriales que no son demostrados y, menos aún, logran conjugarse dinámicamente con el tema de la catedral. Por eso, la sociología del arte no puede pensar la catedral como algo activo, sino como el resultado final de una serie de tendencias exógenas a la obra de arte en sí. El carácter específico es el determinante de la exigencia de un público y de un grado diferencial de los sistemas de valores que 
parecen cambiar en Europa entre el siglo XII y el siglo XIII. Así, se construye el tema sobre categorías yuxtapuestas, históricamente sin fundamento - por ejemplo en la célebre tesis del profesor Arnold Hauser ${ }^{2}$, adjudicando a la catedral el ser un receptáculo de una cosmovisión que ella misma impuso. Los supuestos de este modo de acceso son indesligables de su tendencia insistente a abandonar todo análisis de la obra de arte gótica y de la sociedad de los siglos XII y XIII. Y si lo primero pudiera concebirse como endógeno de la actitud sociologizante, lo segundo termina siendo irrelevante. El yerro de la sociología del arte no se supera intensificando la atención sobre sus postulados, ni corrigiéndose en la línea de clasificación o de análisis. Ni siquiera logra superarse agregando gradualmente a sus tesis centrales, nuevos hallazgos o postulados rectificativos ${ }^{10}$.

El último error sería, por tanto, insistir en el campo experimental de la sociología del arte hasta sus extremos paradójicos. Era necesario reconocer que la catedral era algo más que una obra de arte, y ese algo más se vio en su función estrictamente social que llevaba en su seno. Entendido el proyecto de esta forma, es natural que terminase asumiendo todo un conjunto fenomenal, y la catedral se explicase por su ubicación; sin pensar cómo llegó a estar ubicada allí, esto es, sin desvelar la relación dialéctica que inspiraría su ubicación social con su razón dé ser. Conviene, pues, advertir de inmediato que la expresión que Georges Duby hizo célebre de que «la cathédrale est l'église de l'évêque, donc l'église de la cité, et ce que l'art des cathédrales signifia d'abord en Europe, ce fut la renaissance des villes ${ }^{11}$, debía de entenderse como un punto de partida y no como un axioma interpretativo. Esta idea fue suficiente para emprender un estudio de la coejecución que tenía el desarrollo de la catedral gótica en su seno social.

Aquí se vuelve al problema inicial. La custionable tesis de que la catedral acogía en su seno una Weltanschaung de la

9 ARNOLD HAusER, Sozialgescbichte der mittelalterlicben Kunst Rowohts deutsche Enzyklopadie 45 Hamburg, 1957.

to Cf. Hugo KuHN, Fine Sozialgeschichte der Kunst und Literatur. Kritische Reflexionem zu Arnold Hauser, en Vierteljabrschrift für Sozial und Wirtscbaftsgeschicbte, 43, 1956, pp. 19-43.

" Georges Duby, Le temṕs des Cathedrales. L'Art et la saciéte, Paris, Gallimard, 1976, p. 115. 
sociedad europea entre 1140-1270 fue retenida para dar entrada a una de las más célebres teorías sobre este problema: la del insigne profesor Erwin Panofsky. En una de las series de conferencias del St. Vicent College que tuvo lugar en 1948, y más tarde en su edición como libro en 1951, Panofsky dirigió, bajo el título de Gotbic Architecture and Scholasticism ${ }^{12}$, una mirada que quiere pensar el tema de la catedral globalmente. Esta vuelta a la totalidad intensiva, no se hace esta vez con el auxilio teórico de Hegel, al menos no directamente, sino que se logra, intentando llegar a la dimensión teórica desde la cual se entiende la catedral como el gran experimento de la filosofía escolástica «experimentador-desde-la-experiencia del olvido de la propia obra de arte por la secuencia estilística. Este es el punto de arranque de Panofsky.

Los investigadores de la obra de arte gótica han examinado cuidadosamente muchos de los puntos señalados por Erwin Panofsky, para determinar el nivel de rigor científico, y especialmente para detectar alguna posible forma particular de error. Los trabajos han proporcionado resultados enormemente negativos, pero lo que parece especialmente curioso es que el único caso disponible hoy día de interpretación general del arte gótico permanezca distante de las corrientes de análisis de las obras de arte. Sin duda las observaciones que Panofsky llevó a cabo constituyen un grave atentado al positivismo en su articulación más propia, y sus resultados muestran hasta qué punto eran demasiado restringidos los tipos de estudios sobre arte gótico llevados a cabo en el seno de esta disciplina. Y aquellos de mis oyentes que quieran acusar a Panofsky de temeridad y desatino (según la cortés terminología que el academicismo sigue imponiendo), tendrán sin duda mejor opinión de él cuando sepan que Panofsky hizo todo lo posible para impedir que el tema como tal se escapase de la esfera del análisis artístico. Panofsky estaba convencido (por lo demás, quién no lo está) de que el arte gótico era en esencia una obra de arte, y, más específicamente, una obra arquitectónica: la catedral. Y que,

12 ERWIN PANOFSKY, Gotbic Architecture and Scholasticism, Paris, Editions de Minuit, 1970. Con un postfacio ejemplar de Pierre Bourdieu. Citaré siempre por la edición francesa. 
a lo sumo, tenía que ver con la estructura de significactón del pensamiento escolástico; es decir, y precisando los términos, convino en sugerir la hipótesis de que la obra de arte gótica se conjugaba de alguna forma dentro de la esfera imaginaria de la sociedad europea entre 1140-1270 (que él denominó periodo concentrado) con el resto de sus elementos. Pero poca cosa más. Por el contrario, sospechaba Panofsky (aunque les confieso que yo también) de aquellos colegas que acabaron por sostener que el arte gótico era esencialmente el resultado inevitable de un cierto nivel de las fuerzas productivas.

Básicamente, la tesis central del pensamiento de Panofsky se expresa así: "pendant la phase "concentrée" de ce développement extraordinairement synchronique, c'est-àdire dans la période qui va de 1130-1140 environ à 1270 environ, on peut observer, me semblet-il, une conexion entre l'art gothique et la scolastique qui est plus concrète qu'un simple "parallelisme" et plus genérale cependant que ces "influences" individuelles (et aussi très importantes que les conseillers érudits exercent sur les peintres, les sculteurs ou les architectes......./ Elle s'instaure en effet par la diffusion de ce que l'on peut nommer, faute d'un meiller mot, une habitude mentalen ${ }^{13}$. En esta definición, Panofsky toma la catedral en su sentido global - como había tenido desde la Geistesgeschichte $^{14}$ - y la satura de filosofía de las formas simbólicas (las de Aby Warburg y Ernst Cassirer) para expresar con exactitud su sentido de la frase. La idea del hábito, $\mathrm{y}$ de los habit-forming-force sigue siendo una atractiva tesis, digna de reflexión crítica y de admiración. Pero el envés de una frase de Geistesgeschichte sigue siendo, a pesar de ello, Geistesgeschichte. Tanto Panofsky, como su tesis del hábito, no escapan a la vinculación eidética de la catedral, manteniendo el olvido de ella como-lo-que-es. Pues, aunque la filosofía escolástica pueda determinar la relación que existe entre ella y la catedral, queda por saber (y quizá aquí reside el nudo del problema) quién fue quién determinó a quién: si la catedral

\section{ERWIN PANOFSKY, op. cit. p. 83.}

${ }^{14}$ En especial el importante y decisivo artículo (inicialmente una conferencia) de MAx DvORAK, "Idealismus und Naturalismus in der gotischen Skulptur und Malerein, 1918. Publicado en su Kunstgeschichte als Geistesgeschíchte, München, Piper, 1923. Véase el importante libro de HaNs JANTZEN, Kunst der gotik, Rowoblt Verlag, Hamburg, 1957. 
al pensamiento escolástico, o si éste a aquélla. El sentido de la interacción que ofrece Panofsky - ni paralelismo ni yuxtaposición, sino hábito- es un inteligente escamoteo del problema.

La tesis central de Panofsky sobre la preeminencia del hábito mental del gótico justifica la existencia de la catedral gótica, pero no explica por qué necesariamente tenía que ser gótica la catedral. Menos aún su sentido de ubicación y la fuerza de su intromisión en la sociedad europea. Pero la tesis puede servirnos de guía inicial, como el sentido de la ubicación que caracterizó Duby, para establecer el grado artístico de la catedral.

Para que nosotros lleguemos a detectar un grado de comparecencia más severo de la catedral, debemos aceptar los dos principios, que tras este largo excurso, me parecen esenciales: 1) La catedral es la iglesia de la ciudad y de sus fuerzas productivas; 2) La catedral se desarrolla concentradamente entre 1140-1270, vinculada de alguna forma al pensamiento escolástico. Tal experiencia exige completarse con la introducción de un tercer principio: la catedral es el resultado en-si y para-st de la ideología de la Iglesia.

La introducción de este tercer principio para discernir mejor el problema de la catedral abre un campo insospechado a los temas de análisis. No hay un pensar sistemático de base dialéctica, y junto a él, como ilustración tan sólo, una historiografía de las pasadas opiniones. Pero no hay tampoco, como pretendía Hegel, una sistemática de la lógica del saber que absorba todo el conjunto de opiniones. Hay, pensando en sentido original como haría Heidegger, la historia de un proceso, cuyas iluminaciones son lentamente determinaciones. De ahí que si unimos a la tesis de la catedral como iglesia de la ciudad, vinculada al desarrollo de sus fuerzas productivas, y la tesis de la catedral como absorbente de un pensamiento especulativo-escolástico, con la noción dialéctica de ideología, y más tarde aglutinamos en un conjunto sistemático estos tres principios, podríamos configurar una dimensión diferencial, esto es, de alteridad al tema de la catedral.

Con todo, existe un riesgo: darle una jerarquía de determinación a uno de estos tres principios. Para Hegel, por ejemplo, la historia es el desenvolvimiento del "espíritu» en 
sus diversas manifestaciones (hoy se diría lo imaginario). Contrariamente, para Marx el proceso que se desenvuelve es la relación interna entre las contradicciones de una forma de producción y su estructura aglutinante (aquí, el hábito escolástico). La ubicación de la obra de arte, en la ciudad para el gótico, nos llevaría por sí sola a la tesis de Nietzsche de que la verdadera acción es la presencia de su carácter destinacional (Geschickhaft en expresión heideggariana). Ahora bien, de nuevo la catedral no se deja marginar mediante una refutación de una jerarquía sobre otra. Es el objeto mismo el que nos impone desarrollar la dialéctica nuclearmente, refutando todo tipo de acceso parcial para abrir el campo a lo que se oculta tras el conocimiento de la catedral como-lo-que-es: en la ciudad, forjada por el hábito escolástico y asumida por la ideología eclesiástica. Pero es que el destino de la catedral está en sí misma, porque ella misma es algo en sí: un proceso.

La determinación teórica viene fortalecida por la manera cómo ha sido acogido este tema por la historiografía tradicional. Esta determinación retrospectiva se manifiesta claramente en el conflicto que ha desarrollado en la actualidad la historia social de asiento dialéctico con respecto a las teorías tradicionales que entendían la catedral gótica. El pensar así - querámoslo o no- ha impuesto una cierta tensión en los trabajos, y un responsable miedo a caer en determinismos falsos. Los trabajos actuales pretenden discernir la obra de arte por sus propios medios hermenéuticos, como una sobria posibilidad de acceso dentro del campo propio que la catedral tiene consigo. Es de nuevo el buen camino: no exento de dificultades y, muy especialmente, plagado por doquier de tensiones ansiosas. Muchos creen con sinceridad que esta tensión es hoy día insoluble y que la catedral vuelve a emerger, al filo de la década de los ochenta del siglo Xx - al igual que hizo a finales del siglo $\mathrm{xIX}-$, trascendiéndose como una esencia que busca saberse más allá de las interpretaciones particulares. Busca ejercer la tensión en aquella esfera que determina el origen de la obra de arte. Por eso, el mismo Georges Duby en uno de sus últimos y más profundos trabajos, Saint Bernard. L'Art Cistercien ${ }^{15}$, piensa la catedral

15 Paris, Arts et métiers graphiques, Flammarion, 1976. Véase J. E. RuIZ DOMENEG El origen de la obra de arte feudal. Bellaterra, U.A.B., 1979. 
como algo a-lo-que-se-va, ofreciéndole un sentido, es decir, un conjunto global de posibilidades de entendimiento. Este proyecto culmina con la creación de la catedral como algo que en sí mismo posee la categoría explicativa de la sociedad entre 1140 y 1270 .

Además, el proyecto de Duby es esencialmente un proyecto arrojado. De ahí que asuma la tensión actual que supone saber que la coordinación de todos los conocimientos concretos sobre la catedral arrumba la ultimidad de la preocupación. La subordinación de algunos de los conocimientos que poseemos provoca las reacciones y las discusiones más inciertas. El anegamiento de todos los conocimientos en un ámbito de significación suscita las reacciones naturales que invocan al nivel actual alcanzado por la historia en otros ámbitos. Este carácter límite, que la tesis de Duby asume modernamente, subraya el conflicto entre estos elementos teóricos de interpretación de la catedral, sugiriéndose que su presencia no es una elipsis, y que la síntesis tiene que poseer, de una parte, la ambición de asumir todas las claves interpretativas, y de otra parte, el destino claro de iluminar exactamente el tema de la catedral en su campo propio. Es decir, la naturaleza de la catedral gótica, su razón de ser histórica, su sentido de problema insoluble. Esta iluminación, se hace una vez más, como una exigencia a la cercanía fondal de la obra y el arte. Era el camino que trazó Nietzsche en su Die Geburt der Tragödie. Tomando el discurso en su sentido propiamente lógico, esta obra experimenta el último grado de planteamiento sobre el tema en sí, surgiendo de un retorno violento sobre sí misma. Trágicamente. La catedral, al igual que podía haber ocurrido con la obra de arte ática, se encuentra trágicamente consigo misma para desarrollar algo que lleva en su seno: un discurso.

Antes de exponer este problema, permítanme decir unas palabras tan sólo sobre las raíces históricas en las que surge la catedral gótica. En una palabra, sobre su circunstancia. Ésta es promovida, y por cierto se acrecienta desde el sentido destinacional de la catedral, en la tensión que acusó la naturaleza entre 1140-1270. Como un ejemplo claramente definido, la catedral nos pone delante de la aguda lucha de clases que tuvo lugar en el seno social y que funda una nueva sociedad sobre los cimientos por alteración de la anterior. La 
catedral no está ajena a esta aguda tensión, es ella misma tensión, vehículo y caudal de inteligíbilidad. Es la zona señalada con agudeza, insoslayable, de la gran fuerza que se imponía lentamente en la sociedad europea. A principios de este proceso, concentrado sin duda, pero también convulsivo, se podía estar fuera de lo que significaba la catedral; al final de este proceso, hacia 1270 , sólo cabe una experiencia mundanal ligada a la experiencia histórico-universal que la catedral impuso.

Todo este proceso, difícil de describir ${ }^{16}$, denso y agudo, fundamental por su sentido destinacional, tuvo lugar en menos de ciento cincuenta años, y en el suelo europeo. Es la gran diferencia. Y la gran distancia. Ninguna sociedad, ni siquiera la griega, soportó en su seno una convulsión de tanta envergadura. Ocurrió entre 1140 y 1270 , cuando en una de las regiones más prósperas de la cristiandad latina, se desenvolvió, envolviendo (Ein-bolen) una imagen del mundo, un sentido de la realidad, una nueva concepción antropológica, que pensó la sociedad en una dimensión extrañamente nueva, y la lanzó hacia el porvenir, negándole el pasado y la significación del pasado. Pensar linealmente, y no circularmente, ya es de por sí una revolución del campo existencial y mundanal. Destinar al hombre fuera de su cosmos, ligándolo solamente a la esfera imaginaria de sus creencias, es ponerle en camino hacia otro mundo que no le pertenece ni domina. Entre 1140 y 1270 la convulsión social y material alteró sistemáticamente la esfera de propiedad mundanal de los hombres. Arruinó para siempre los sistemas normativos que habían acompañado la realización del universo feudal, y estos fueron sustituidos casi de inmediato y de forma imperceptible, por una visión del mundo coherente y sistemática, la de la Iglesia. Fue un sistema ideológico, cultural y social. Por ello el gótico no será llevado hacia el humanismo como su producto, pero tampoco invalidado cuando éste llegue, será simplemente transformado a las conveniencias naturales de su momento. Esta es la gran dimensión ideológica que se crea, al margen de sus contornos formales. El gótico está por encima de. ser un estilo artístico, o una simple

${ }^{16}$ Aunque modélicamente lo ha llevado a cabo recientemente GEORGES DuBy en su Les trois ordres ou l'imaginaire du feodalisme. Paris, Gallimard, 1978. 
comprensión cultural: es una totalidad omniinclusiva. Una voluntad de poder. Esta no se deja echar hacia atrás; ni negar; ni sorprender. Como voluntad de poder, el gótico asume el mundo trágicamente, haciendo circular por doquier la verdad de su construcción sistemática.

Este es el nudo de la tensión que se experimenta suficientemente en la circunstancia creativa en la que se inscribe la catedral. Ésta acoge en su seno el crecimiento agrícola y la alta movilidad vertical y horizontal de este periodo alterado y de ruptura. Esto significó además que, en nombre de la conciencia elaboradamente racional que se impusieron, los oficionarios más cultos de la Iglesia, atacaron las formas arcaicas y feudales de la existencia, pero también (y aquí reside uno de los puntos más decisivos) las salidas falsamente operativas a la crisis de los sistemas normativos feudales ${ }^{17}$. La ideología de la Iglesia sospechará por igual de la nostalgia arturiana, de la austeridad cisterciense o de la subjetividad patética de los seguidores de Abelardo. En nombre de su propia actitud, entre 1140-1270, desarrolla la idea del poder ligado a la institución inicial del gótico: el poder del rey y la corte. La Iglesia se convirtió en el receptáculo de la verdad y de la angustia de los hombres. Predicando la pobreza evangélica y la obediencia, pretendió desarrollar el modelo monástico, fuera de sus contornos institucionales. Convirtió la esencia de su pensamiento en una ideología estructural, multiforme, cuya presentación era novedosa a cada momento y circunstancia vital. Trágica. La racionalidad de sus actos y de su pensamiento quiso ordenar el mundo. Ordenar era reclasificar de nuevo los objetos y las personas. El gótico acepta este arrojamiento vecino a la esencia de su ser-arte. El significado de toda la acción se transformó rápidamente en un discurso ansioso de victoria, no sólo con respecto al mundo que debía de arruinar, sino también de todos aquellos movimientos de rectificación de aquel mundo que, por desmesurados, eran virtualmente heterodoxos. Entre 1140 1270 , la Iglesia concibió un orden justo y moralmente bueno, con algunas connotaciones ascéticas, pero siempre vinculado a la realidad que lo hizo posible, que naturalmente

17 Cf. Karl. BosL, Gesellschaftswandel, Religton und Kunst im haben Mittelalter. München, 1976. 
no fue la duda, sino, y lo subrayo con energía, la voluntad de poder.

El mandamiento divino de mantener el orden como Dios creó un orden celestial, se interpretó como una exigencia de perfección social, de sublimación ética y, sobre todo, de construcción estética. Y puesto que estas tres funciones de un mismo aspecto entre 1140 y 1270 eran un ideal, y no una realidad, se puede decir que el discurso eclesiástico en este momento fue rigurosamente imaginario, es decir, ideológico.

La gran novedad que supuso el discurso de la ideología de la Iglesia entre 1140-1270 no fue tanto el descubrimiento de una visión del mundo coherente y estrictamente eclesiástica, sino la forma de cómo se advirtió este discurso. Casi sorprendentemente, los conceptos teóricos que hicieron posible el desarrollo y la difusión de este discurso no tuvieron su receptáculo en la naturaleza misma de la palabra. El discurso de la ideología de la Iglesia entre 1140-1270 no fue un discurso de la palabra, sino un discurso de la piedra: la catedral gótica.

Debe tenerse esto en cuenta: la catedral gótica es el resultado de un proceso que ella misma lleva en su seno. Las normas intelectuales que la rigen son sus propias normas de construcción estética. No existe una idea previa que concibiese la catedral, y a partir de ella se construyeran catedrales. Todo está ligado estrechamente al proceso mismo de la catedral, en que la verdad del pensamiento eclesiástico quiere llegar a ser expuesta petréamente, y en el que el pensar se fortalece en la contemplación de la ejecución de esta obra. Tal vez fue la catedral quien articuló la estructura del pensamiento escolástico, y no a la inversa. En todo caso, cronológicamente es así. Con ello, además se sitúa el lugar exacto que tiene la catedral dentro de su mundo. Ella misma es un discurso-procesual, cuyo inicio se conoce pero no su final: he ahí la adaptabilidad a diferentes momentos, geografías o circunstancias. La catedral es ella misma un proceso discursivo, retórica del saber eclesiástico y de la ley moral que quiere imponer. La catedral es, repito una vez más, bacia-loque-se-va, santuario que no sabe cuál va a ser su destino final. Las cosas en las que se asienta las va lentamente descubriendo. No están determinadas de antemano ni por una idea, ni 
por un sistema constructivo, $y$, menos aún, por una visión social del mundo. La catedral gótica sabe, al construirse ya el coro absidial de Saint-Denis entre 1140-1144, lo que no quiere, pero difícilmente ha logrado abstraer lo que quiere en una ley estética de orden general. La catedral no tiene esa guía, ni siquiera un contenido ético u óntico que la condujese. Ella misma es su propio contenido. La ideología de la Iglesia inscribe toda su experiencia en la construcción de la catedral, como su elemento de orden y de aculturación: es el receptáculo perfecto para penetrar en un mundo, no lo olvidemos, cuyo vehículo de comprensión no era la escritura, sino la imagen y el sonido. La catedral rechaza, mediante los elementos característicos de una época arcaica, no sólo lo impuro del arcaismo, sino cualquier elemento demoníaco. Si el reino de la verdad va a ser a partir de ahora luz, es lógico que la oscuridad de la noche sea juzgada de forma negativa, trágicamente, rechazándola hasta un lugar imposible, e incluso hasta el silencio.

El discurso de la catedral, y más aún la ley moral que llevaba en su seno, substituye lo tremendum y lo fascinosum de la sacralidad, por la blancura de los árboles de la vida que las ojivas verticales ansiaban ${ }^{18}$. Lo-santo del mundo pierde su vitalidad, su misterio, su razón de ser; y crea una distancia entre el hombre y el universo. Esta distancia es la catedral gótica.

Esto debe ser un hecho inexcusable: el discurso de la catedral gótica ordena todo lo perceptible de la sociedad; aunque también lo ígnoto y nocturno. A través de la catedral se imponen unas nuevas normas y unos nuevos sistemas de valores. E igualmente se organiza a partir de ella la sociedad, haciendo posible la desaparición del señorío como unidad política y dando lugar al Estado. La catedral situada en el centro de cada región próspera, de cada ciudad avanzada, sirve de punto de apoyo, de esquema director al que se refiere cualquier observación de la existencia o cualquier comparación de las estructuras visibles de los grupos sociales

${ }_{18}$ Para la idea de lo tremendum y fascinosam, véase Rudolf OTTO, Das Heilige. Uber das Irrationale in der Idee des Gottlichen und sein Verbaltnis zum Rationalem. Gotha, Klotz, 1929. Para el carácter pétreo de las ojivas, y los árboles de la vida, véase ERNST BLOCH, Das Prinzip Hoffnung, Frankfurt, Suhrkamp 1976, vol. II, pp. 819-850. 
y de sus categorías institucionales. La catedral es ella misma visión del mundo. Pero también teoria social y política. En torno a la catedral se hizo posible un etbos del trabajo específicamente urbano y burgués (y no a la inversa, como ingenuamente se ha sostenido), armonizando la función municipal, la gremial y la nobiliaria. Ya no existen tres funciones, sino tres estamentos. De igual forma, convirtió en dueños del destino histórico a los portadores de la técnica y del saber-hacer que lo pusieron al servicio de la elevación de las catedrales. De aquí surgió entonces (y también ahora) el mito del racionalismo medieval, que sedujo a Viollet-Le-Duc en el siglo pasado ${ }^{19}$. ¿No es esto ideología en sentido preciso? Sí, por cierto: es la ideología que piensa la sociedad entre 1140-1270 desde la seguridad del poder. Pero es, al mismo tiempo, la ideología la que está sugiriendo todo el proceso cultural del hombre de este periodo: coordinando su sentido de la existencia y de la verdad ontológica. Pero, ¿esta coordinación no está y no cae entonces en el sentido de la iluminación que la catedral lleva en su seno? Así es, sin duda.

En Saint Bernard. L'Art Cistercien, Georges Duby sugiere que todo discurso rebota sobre la sociedad para articularse: "L'école prit donc aisément le relais du cloître. Elle tendait au même but, aider l'âme a quitter les provinces de la dissemblance, et par les mêmes démarches. Ne fallait-il pas traiter la masse rude, informe, désordonnée que constituait dans son inculture la pensée du peuple laic comme les cisterciens traitaient la Silva? Defricher, émonder, rectifier? $\${ }^{20}$. La catedral es la única realidad del mundo y de su sujeto activo. La iluminación es aquí fundamentalmente la sistemática exclusión de un mundo que no sea racional. Ella es guardián de un pensamiento dialéctico y de un espíritu de

(9) En su artículo "Architecture» de su Dictronnaire de Pédagogie, escribió Viollet-le-Duc: $\alpha^{r}$ sagissant contre l'influence exagérée des monastères, les évêques de Frau. se liquèrent avec les villes, sièges épiscopaux, pour résister aux empiét ments du pouvoir monastique: les cathédrales bàties de 1160 a 1250 sont le signe visible de cette alliance. La direction des bâtiments religieux est enlevée aux-moines, et c'est alors que prend naissance une architecture dont les principes sont absolument établis sur le raisonnement et la science. C'est ce qu'on apelle le style gothique... il appartient à la population laique du 12 sièclen. Citado, y comentado, por HANS SEDLMAYR, Die Entstebung der Katbedrale, cit, p. 349 ss.

20 Georges Duby, Saint Bernard..., cit., p. 202. 
cálculo, porque en este pensar hay algo de sencillo que introduce al hombre a la cercanía de lo religioso y del acto litúrgico central. Los mismos capiteles representan, en su imaginaria monstruosidad, como estudió Jurgis Baltrusaitis, aquello que queda por pensar: el resto imaginativo e imposible de un mundo ajeno a la luz y a la razón que la catedral impone $^{21}$. La exuberancia feudal, que el mismo románico quiso asumir dinámicamente, queda excluida por la estructura del pensamiento gótico, que hace primero la catedral y más tarde la escolástica.

Sólo que la estructura de este pensamiento aparece como una alternativa rígida y, especialmente profunda al filo del periodo concentrado. Duby ha insistido más de una vez que es en Laon donde hay que empezar su análisis. El obispo Gautier de Mortagne forma los conceptos complicados y difíciles que penetran en el pensar nuevo del gótico. Experto en dialéctica hace desarrollar la habitual enseñanza, la de Juan de Salisbury o la de Hugo de San Victor. Es la correlación inicial de un pensamiento discursivo. La energía misma de la catedral. Tal vez en su evolución se puede encontrar la vinculación tan estrecha que la catedral gótica tiene con respecto a la génesis del poder moderno: el poder del rey. La textura de los muros, la altivez de sus pináculos, la posibilidad de su utopía vertical, todo señala la grandeza del rey, soberano de la tierra, analogía perfecta, del soberano, rey de los cielos. El desarrollo exterior de Laón, indica Duby, "demeure ce qu'il lui convient d'être, royale, militaire, dominante ${ }^{22}$.

Esta es la gran exigencia: dominar, mediante la voluntad de poder que emerge como trágica acción sobre la sociedad y el cosmos. El esfuerzo intelectual no tiene precedentes en la historia de la humanidad y su pasión termina por ser una pesadilla a lo largo del siglo XIII, y cada vez con mayor celeridad. En esta época, las cosas cambian muy deprisa, excesivamente convulsionadas. Entre tanta pasión por dominar el mundo, se construyen catedrales. Es el símbolo de este dominio y de la seguridad en la "nueva" existencia

${ }^{21}$ Jurgis Battrusartis, Reveils et Prodiges, Le gotbique fantastique, Paris, Armand Colin, 1960.

${ }^{22}$ GEORGES DUBY, Saint Bernard..., cit., p. 206. 
racional y lúcida. La catedral, se dice, termina siendo un callejón sin salida. ¿Es una crisis económica o ideológica la que la frena en década de los ochenta del siglo XIII? Dejemos discutir aún estas opiniones enfrentadas. Roberto Sabatino López ofreció un indicio extraordinario al analizar el caso de Beauvais: ese ejemplo saberbio de la ambición, esa bóveda de 48 metros que estrepitosamente se derrumba en $1284^{23}$. Ahora bien, para entonces, el pensar a través de la catedral ya ha pasado; pero en el intervalo, durante el periodo concentrado, entre 1140-1270, los hombres creyeron en ellas y sus pináculos, sus bóvedas altivas, sus muros transparentes manifestaron la iluminación de un mundo en el que se confiaba. Un mundo que sustituyó imaginariamente el poder del hierro de la espada feudal por la fuerza mágica del cristal. Lo invisible del castillo transparente, de la catedral como supuesto total y omniinclusivo, fue el armazón de un modelo social que significó la distancia entre un mundo arcaico, como el feudal y un mundo moderno, como el renacentista. Esa gran distancia es el indicio temporal. O como dice Georges Duby, "la conciencia de la relativi-

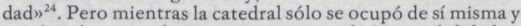
amplió el campo de las experiencias y de las posibilidades, entre 1140-1270, la verdad del mundo quedaba encerrada en sus muros, asegurada por sus sonidos maravillosos, quebrada por la dureza de sus plegarias y de sus signos misteriosos. Por eso el "filosofar» escolástico sobre el mundo se concibió en la misma intensidad y el sentido de dominio que la ideología de la Iglesia había otorgado a la catedral gótica. Para este pensamiento, lo justo era responder a las mismas exigencias reales o imaginarias de la catedral. Ya fuera como Roberto Grosseteste que reflexionó sobre la teoría de la luz y del mundo maravilloso del cristal, ya fuera como Tomás de Aquino que desarrolló un discurso sobre la verdad que

2) Roberto S. LoPEz. "Economie et architecture médievales. Cela aurait-il tué ceci?, en Annales, E.S.C., 1952, pp. 433-438. Por el contrario, JaCQues Le Goff, La Civilisation de P'Occident Médieval, Paris, Arthaud, 1965, parece pensar que el hundimiento podría indicar el símbolo de la decadencia del arte gótico, seducido por lo desmedido y la búsqueda de las dimensiones colosales.

24 Georges DuBY, "L'Histoire des systèmes de valeurs", en History and Theory, núm. 11, 1972, pp. 15-25. 
encerraba el universo temporal y espacial de la catedral gótica. Todo ello, únicamente al servicio de una visión del mundo, confesada ya de lleno cuando comenzaron los balbuceos de la catedral gótica, esperando callar con ella todas las disidencias, las nostalgias e incluso el silencio.

Si el reino de la verdad se vinculó estrechamente a la catedral, y antes de que ésta se convirtiese en un callejón sin salida, es decir, durante el periodo concentrado, cabe preguntarse sobre esas misteriosas referencias de la significación que la catedral gótica parece tener. Juzgar sus contenidos imaginarios es recorrer de nuevo ese espacio plateado que fue entonces, y sigue siendo, el espacio de la catedral gótica; es, asimismo, una ansia por recorrer el mismo camino de la experiencia teórico-intelectual que los góticos tuvieron sobre su mundo. Advertir esa voluntad de poder trágica como una pasión infinita de desvelamiento de lo misterioso del mundo a través de su caudal de inteligibilidad. En pocas palabras, abrir un camino adecuado al fundamento simbólico que la catedral tiene, en su contenido específico. Es decir, explicar con rigor por qué la catedral es gótica. En las excelentes páginas de Josef Sauer y de Hans Sedlmayr se encuentra una interpretación referente al sentido simbólico de lo gótico de la catedral $^{25}$. Al fin y al cabo, la actitud que parece recobrarse, aunque ideológicamente, en la construcción de la catedral, es una certeza religiosa de sublimación de la existencia y el mundo. De ahí que la pregunta para un historiador social vuelve a tornarse directa: ¿Cuándo y por qué la catedral se convirtió en el vehículo de unión entre el hombre y la divinidad? Teniendo presente que cuándo y por qué son dos interrogantes genuinamente históricos. Este tipo de pregunta ayuda aún hoy a abrir el camino que determine por qué la catedral es gótica.

El pensar que el discurso de la catedral llevaba en su seno, no define su valor simbólico. Es preciso comprender el fin que se buscaba desarrollar al plantear un tipo de construcción artística en donde lo esencial consistía en la imposición total de un campo vísual y de una visión del mundo. Esto

25 JoSEF SAUER, Symbolik des Kircbengebaudes und seiner Austattung in der Auffassung des Mittelalters. Freiburg im Br., 1924. H. SEDLMAYr, Die Entstebung der Kathedrale, cit. pp. 95 ss. 
quiere decir, y retornando al arrojado proyecto que Georges Duby desarrolló en su Saint Bernard ¿ por qué la catedral logró imponer el discurso que el cisterciense no pudo desarrollar? ¿Era por la legitimización de lo racional contra lo caóticoarcaico? No, pues el mismo discurso de San Bernardo y la vía cisterciense, tenía en su seno esta actitud. ¿Era la pureza de las líneas góticas? No, pues el movimiento cisterciense fue la búsqueda misma de esa pureza. La contraposición reside en la dimensión que asume la voluntad de poder. Lo que en el cisterciense fue agonía y patetismo, en el gótico fue tragedia. El gótico no queria combatir, sino dominar. Duby lo ha dicho ejemplarmente: "L'évêque no doit pas s'écarter du monde, mais bien l'affronter, le dompter, se dresser face à lui comme jadis ses devanciers face a un déferlement des hordes barbares, le civiliser, l'enseigner, le soumettre, le ramener a la droiture dans l'ordre de Dieu. L'évêque est le conducteur du peuple» ${ }^{26}$.

La catedral entiende el pensar como el representar de un mundo superior. "Ce message - termina Duby-lancé aux foules inquiètes justifie l'école et la parure où le discours logique vient s'immobilisern ${ }^{27}$.

Este pensar emerge con lucidez en la poesía altoalemana de los siglos XII y XIII según se desprende del inteligente trabajo de Heinrich Lichtenberg ${ }^{28}$. En estas poesías se encuentra la cualificación del objeto de la catedral y de su exigencia de ser gótica. Ser gótica es expresarse desnudamente mediante un sonido objetualizado en unos muros diáfanos. La ofrenda que la catedral desarrolla frente al mundo, es su símbolo del carácter celestial, la dialéctica perfecta entre un sonido, la música contrapuntística que comienza con Leoninus y Perotinus, y las vidrieras de colores. Este es el valor de lo gótico, utopía del más allá, sueño plácido de un valorar positivo la unión mística de un mundo. Canto celestial sobre su profunda hendidura de ser. Iluminación de su esfuerzo por cristianizar la sociedad y la cultura. El gótico es exigencia de una parousía que anuncia la

26 DuBY, Saint Bernard..., cit., p. 206.

27 Ibídem, p. 207.

28 H. LichtenBerg, Die Arcbitekturdarstellungen in der mittelboscbdeutschen Dichtung, Münster i. W., 1931. Véase también Hans Sedtmayr, op. cit., pp. 85 ss, 170 ss. 
presencia de Dios escatológicamente. Según se desprende de las páginas de Die Enstehung der Kathedrale, la bella y discutible obra de Hans Sedlmayr, el gótico termina siendo una preocupación subjetiva sobre la verdad del arte que duerme en la obra de arte, que duerme en la catedral. El pensar así, como símbolo de la unión de Dios y el mundo, es el pensar gótico. De ahí que sintetizando esta realidad (que Jantzen, Sauer, Panofsky, Sedlmayr, Grodecki y otros tan excelentemente han estudiado) emerge la luz de la verdad del ser contra la subjetividad de la existencia, de la que la catedral se hace simple objeto, simple obra de arte. La remisión al arquetipo celestial es nostalgia sin duda de un mundo que ya no existe, pero también es exigencia de lo iluminado trágicamente. En una sola palabra, su presencia (que en alemán se diría Gegenwart, literalmente, lo-que-está-ante-uno ${ }^{29}$. Esta presencia es el signo que la catedral impone como liturgia y canto místico. Su fondo destinacional. Su mundo como determinación de otro superior: La voluntad de poder trágica.

Por lo tanto, con la actitud del discurso gótico que la catedral llevaba en su seno, la Iglesia contrapuso trágicamente dos conceptos claves en el mundo simbólico: lo negro y la claridad. Para la Iglesia, sobre todo cuando se analiza con detención las razones de la construcción de cualquier edificio gótico, la negritud es el atributo del mundo del pasado, del universo arcaico donde el canto de la piedra era significación de una apertura directa al cosmos. El cuidado que siente por esta actitud es el límite de su valor simbólico, pues la catedral, al ser gótica, asume la nueva forma de ubicar al hombre "en" el universo. Y ello se lleva a cabo en un diálogo con su elemento simbólico: la catedral. La ruptura del principio silencioso del mundo arcaico se introdujo junto a la iluminación del espacio santo que para el pensamiento

29 Así se expresa el mismo HaNS SEDLMAYR, al principio de su importante Die Entstbebung der Kathedrale, cit., p. 13 cuando escribe: «Der Zeit genügte das Abgeschlossne des früheren Kultusses, seiner Erscheinung, seine bauliche Form nicht mehr; sie verlangte nach einer innigeren Vergegenwärtigung des Heiligen und Uberrirdischen, nach der unmittelbaren Năhe der wundervollen Geheimnisse, welche das Reich himmlischer Gnade zu erschliessen geeignet waren. Das Leben selbst sollte sich im Widerschein solcher Nahe verklaren». 
gótico, y para la catedral, es lo que emerge desde la esencia arrojada del hombre en la tierra, desde el pecado original. El ser-si-mismo-en-el-mundo gótico (permítaseme esta paráfrasis de tipo heideggariano) asienta su circunstancia mundanal con el cosmos a través de la anión simbólica que hace posible la catedral. La dimensión iluminada de su vida, es el canto santo y la experiencia visual. Al entrar en el espacio sagrado que la catedral desarrolla, el ser piensa góticamente, es decir, se abre hacia lo santo a través de la luz y el sonido.

Este planteamiento discursivo-estético que permite la catedral y la obra de arte gótica, abrió todas las posibilidades para la construcción de las catedrales góticas, al desarrollar en sí mismo los dos principios fundamentales de su sistema constructivo: la polifonía sonora que enciende las naves y las vidrieras que permiten subrayar la diafanidad de los muros. Entre estas vidrieras multicolores y el ritmo musical se encierra todo el universo gótico y la experiencia diamantina de la catedral. En el centro de la nave mayor, y como culminación de los dos principios fundamentales, emerge la tercera función sublimante del sìmbolismo gótico, el rosetón que, como señala Duby, «au centre de la rose, au terme des progrès de l'âme, revêtue des insignes du roi et de ceux du prêtre enseignant: la sagesse l'identité retrouvée grâce a la raison $s^{30}$.

Identidad, sí, la que aparece en las naves desnudas y en la simplificidad del muro. Este equilibrio que permite el gótico es su partícípación con lo santo como unidad del pensamiento. La catedral se recubre por doquier de objetos, esculturas, marfiles, que no son santos por sí mismos, sino que, sólo lo son porque se relacionan y comparten la unidad de la catedral. Únicamente son santos cuando se niegan a sí mismos para aglutinarse en la realidad absoluta que supone la catedral. De ahí que la tentación del gótico sea conceder certeza a este principio y llegar por este camino a considerar que los objetos son santos por sí mismos. Cuando estos objetos dejan de estar subsumidos en la catedral se transfor-

${ }^{30}$ DuBy, Saint Bernard,., cit., p. 207. Véase igualmente el último y bello libro del mismo autor, L'Europa an Moyen Age. Art Roman, art gotbique. Paris, Arts et Métiers Graphiques, 1980 cap. 4, La Cathédrale, la ville, l'école, pp. 107 134. 
man en ídolos. La santidad que era un ansia gótica, provocó a principios del siglo XIV la idolatría.

La investigación de la catedral gótica está por hacer. Yo he querido presentarles esta mañana el diseño de lo que puede ser. Diseñar no es concluir. He abierto naturalmente todo el campo de experiencias posibles para determinar el ritmo y la dinámica de la historia de un elemento omniinclusivo, la catedral gótica. Creo que en esta lección se han puesto de manifiesto muchos de los problemas con los que el investigador del tema de la catedral va a encontrarse. De igual forma, he subrayado conscientemente la exigente necesidad de recurrir sin ningún tipo de prevención a los modelos interpretativos que el pasado historiográfico nos ha legado, incluso estando metodológica y teóricamente muy alejado de algunos de ellos. Eran apoyos necesarios. Quien piense que esta lección además ha girado insospechadamente hacia conceptos y elementos filosóficos, he de decirles que para detectar el arte gótico, y muy especialmente la catedral, el historiador debe recurrir más a la filosofía que a la sociología. Duby hace años indicó que los movimientos de profundidad que hicieron modificar entre 1140-1270 la creación artística no salieron del estrecho círculo de los clérigos y abades que pensaban filosófica y escolásticamente. Era natural. La catedral, lo hemos tenido ocasión de comprobar a lo largo de esta lección, es el vehículo decisivo de la configuración de una ideología de poder de la Iglesia y de una estética determinada: la de la escolástica. Pero la catedral es el vehículo operativo inicial: ella misma es el discurso que conduce a la ideología de la Iglesia a la estética escolástica y a la inversa.

$\mathrm{Y}$ ahora, aquéllos que tienen lagunas en la mente dirán - quizás porque suena aún bien-que esto que he hecho esta mañana es Geistesgeschichte.

Es natural que algunos sigan pensando así. Sobre todo aquéllos que consideran la catedral como el resultado directo de una circunstancia social. Lo extrañamente imposible 
de este pensamiento, que por fortuna está en trance de desaparecer, reside en la dificultad al que lo somete la propia catedral gótica. No sólo porque la catedral se nos escapa partiendo de lo social como supuesto categorial; sino también porque dejamos oculto el tema del gótico. Justamente por ello me mantengo firme en mi pensamiento sobre la catedral y el gótico, y sugiero que el impulso de acción que llevó a los hombres a profundizar en una actitud de alteración ante el mundo feudal se inscribe en una trágica visión del mundo. La voluntad de poder colisionó con el destino aristocrático, y ambos se autodestruyeron para posibilitar un mundo nuevo: el Renacimiento. La distancia que crea la catedral es lo inexcusable de su realidad histórica entre 1140-1270. Más acá de esta fecha aún era posible retornar sobre las sendas de un mundo donde las rocas eran castillos y la seguridad se basaba en la firmeza de un sistema de parentesco. Más allá de esta fecha, el universo imposibilitó la vuelta hacia el mundo. Y lo lanzó hacia el futuro. La utopía que la catedral había desarrollado arquitectónicamente comenzó ahora a abrirse campo fuera de las fronteras de la humanidad. Hacia 1271 Marco Polo viaja a China. Y los genoveses han logrado cerrar el círculo comercial de una bistoria que no se ve, en el decir de mi gran amigo Geo Pistarino, para ampliar el caudal de una utopía social y real.

En medio de este momento histórico, en el periodo concentrado entre 1140-1270, la ideología de la Iglesia buscó, a partir de la catedral gótica, un movimiento imaginario para escapar del tiempo, paralelo a la aventura del Graal y contradictorio con ella. Porque mientras ésta se pierde para siempre en el tiempo de lo nunca, la catedral, al buscarlo con vehemencia, hace inevitable el tiempo lineal del futuro. Inexorablemente la historia como progreso escatológico, inmanente o trascedente, se abre para el europeo. Antes de renacer al filo del 1300 , desarrollará una aventura insólita, no imposible, pero sólo accesible para los iniciados. Una aventura racional: la catedral gótica. Era la aventura enamorada de la claridad.

Aquí se inscribe la respuesta final a la pregunta básica e inicial de esta lección: ¿La catedral gótica tiene algún significado social? Sólo provisionalmente debería responderse en lenguaje poético. La pregunta exige una tercera 
dimensión de respuesta. Exige saber por qué la catedral gótica era, y es, en cierta manera, el destino mundanal del hombre al filo del 1140, y quizás nuestro destino actual. ¿Por qué lo gótico puede aún hoy tener un sentido social? El carácter de copertenencia que la catedral tiene por ser una obra de arte, y ser una obra de arte gótica, es el rigor que impone a su reflexión lógica, a la cuidadosa solicitud por la elevación y por el ansia de una perfección del mundo que se eleve hacia Dios, o hacia el infinito. Es el tiempo, donde el mito y la fase heroica de una técnica se encuentran. ¿No es acaso espíritu gótico, solicitud de la catedral, la pasión técnica por la ascensión vertical hacia el universo conmensurado de la relatividad la que conduce al hombre actual a admirar el Concorde? Hay que acostumbrarse a no supervalorar nuestros mitos e infravalorar los del pasado. La catedral era ansiedad manifiesta de esa verticalidad, y su técnica quiso ansiosamente darle una razón de ser. No hay que exigirle demasiado a la sociedad entre 1140-1270, ni siquiera hay que desmitificarla como si fuésemos un Jean de Meung tratando de concluir el Roman de la Rose. Es necesario en la actual penuria tecnológica del mundo, y de la situación fronteriza con la negación, pensar solícitamente en el mito vertical de la ascensión celeste; por igual, y frente a la literatura de finales del siglo XIII, la catedral se manifiesta como articuladora de un mundo y de su mito; aunque no fuese el futuro, sino un sueño utópicamente irrealizable.

La catedral gótica buscó fundamentalmente la claridad. La retórica intelectual de la Iglesia, entre 1140-1270, creyó haber encontrado que fuera de la catedral no había nada, y que los intentos de nostalgia se habían ya perdido en el bosque imaginario y circular de Brocelandia. Frente a ellos, la catedral supuso la exigencia de un árbol de la vida nuevo. Los surcos que traza, como señaló Ernst Bloch, son una especie de discurso de ascensión vertical de la piedra que crea undentro perfecto y sagrado, el de la catedral. Entre sus muros de piedras preciosas, según la experiencia imaginaria y ansiosa de los ideólogos de la Iglesia, volvió a resurgir desde los abismos de su destrucción la idea de la fiesta escarlata, que se convirtió en el ritual específico de la religión cristiana. La catedral se sublima en el acto central de la misa, ofreciendo su imagen, el recaptáculo fascinante al misterio primor- 
dial, el de la Encarnación de Dios. Resplandor sagrado que aparta las ramas de los árboles para dar entrada a los arbotantes y a los cruceros pétreos, desvaneciendo sueños y sustituyendo para siempre el hierro de la vida por el cristal.

La catedral fue en último término el sustituto activo del mito del graal. Por ello entre la diafanidad de sus muros y la sonoridad de su música se hizo realidad para la ideología eclesiástica y para la estética escolástica, la Visión del Viernes Santo. Surcando para siempre un mundo sobre la piedra sagrada de los arbotantes y los cruceros. Todavía hoy, si agudizamos el oído al entrar en Chartres o en Leon, o en York, escuchamos como una plegaria con ritmo mesurado voces que gritan:

Höchsten Heiles Wunder

Erlösung dem Erlöser! 